http://jmscr.igmpublication.org/home/

ISSN (e)-2347-176x ISSN (p) 2455-0450

crossref DOI: https://dx.doi.org/10.18535/jmscr/v8i10.43

Journal Of Medical Science And Clinical Research

IGM Publication

An Official Publication of IGM Publication

\title{
Acute Methyl Alcohol Poisoning: A Case Report in a Tertiary Hospital, Visakhapatnam
}

\author{
Authors \\ Dr Bethanapalli Mounika ${ }^{1}$, Dr Y Gnana Sundara Raju M.D², Dr Tati Hyma ${ }^{3}$ \\ ${ }^{1,3}$ Post Graduate, Department of General Medicine \\ ${ }^{2}$ Professor, Department of General Medicine
}

\begin{abstract}
Background: Methyl alcohol poisoning is an extremely hazardous poisoning commonly occurs via oral ingestion of illicit or adulterated liquors or as ethanol substitution. Toxicity results in gastrointestinal manifestations, metabolic acidosis, neurologic squeal, and even death. Early management with bicarbonate, ethanol and hemodialysis in patients having significant toxicity will decrease mortality and improves patient's outcome.

Materials and Methods: A case report of 15 patients admitted in King George Hospital, Visakhapatnam with history of intake of illicit liquor with progressive high anionic gap metabolic acidosis, altered sensorium and visual symptoms which improved with treatment with bicarbonate and hemodialysis.

Results: Out of 15 patients admitted, 12 patients had metabolic acidosis and treated with bicarbonate. Two patients improved with bicarbonate treatment and eight patients underwent hemodialysis for the improvement of symptoms. Two patients with hypotension and altered sensorium could not be recovered and expired.

Conclusion: Methanol exposure is an acute poisoning in which toxicity is due to metabolites like formate, which is the primary reason for acidosis. Diagnosis is based on suspicion of ingestion of illicit liquor, the presence of visual disturbances, metabolic acidosis with elevated anion and osmolar gaps. Treatment with bicarbonate and hemodialysis significantly improves the mortality and morbidity.
\end{abstract}

\section{Introduction}

Methanol also known as methyl alcohol, woodburning alcohol, or carbinolis a highly toxic agent used in paints, varnishes, solvents, plastic manufacture, photographic materials, antifreeze, and household cleaning products. Outbreaks of methanol poisoning mainly affect poor and vulnerable strata of society.

The pathways for poisoning are inhalation, cutaneous, and digestive tract, in most cases by swallowing. Methanol is rapidly absorbed from the gastrointestinal tract, giving peak plasma levels after 30-90 minutes. The serum half-life ranges from 14 to 30 hours and is distributed freely. methanol is metabolised by enzymatic degradation by dehydrogenase into formaldehyde and formic acid, which are responsible for most of the symptoms of methanol poisoning. Patients present with signs and symptoms of toxicity usually 12-24 hours after exposure. Treatment should be initiated based on the bicarbonate and lactate levels, and base deficit as methanol levels cannot be obtained immediately.

\section{Materials and Methods}

This is a case report of 15 patients admitted in a tertiary hospital, Visakhapatnam with a history of consumption of illicit liquor. A detailed history and clinical examination were done. Patients of age group 18-55 years, and both sexes are present. 
Routine blood investigations like complete blood count, RFTs, complete urine examination and $\mathrm{ABG}$ are done for all the patients. In patients with $\mathrm{pH}<7.3$, intravenous bicarbonate was given as per calculated dose. Intravenous crystalloids and inotropes were given for patients with hypotension. Hemodialysis was done for patients who did not improve with bicarbonate therapy.

\section{Results}

A total of 15 patients of methanol poisoning, 12 (80\%) males and $3(20 \%)$ female patients, were admitted in a tertiary care hospital of Visakhapatnam. Two died before reaching the hospital. Patients are of age between 18-55 years. All patients are brought to the hospital after 12 hours of methanol intake. Gastrointestinal symptoms like nausea, vomiting, and abdominal pain were observed in $6(40 \%)$ cases followed by neurological symptoms in the form of altered sensorium in 2 patients (13.3\%).Visual symptoms like blurred vision is seen in $1(6.6 \%)$ patient and had normal fundus on fundoscopy. Neurological symptoms are seen in patients with methanol poisoning who did not survive.

\begin{tabular}{|l|c|}
\hline Clinical profile & Number (\%) \\
\hline Gastrointestinal symptoms & $6(40 \%)$ \\
\hline Breathlessness & $6(40 \%)$ \\
\hline Blurring of vision & $1(6.6 \%)$ \\
\hline Hypotension & $2(13.3 \%)$ \\
\hline Altered sensorium & $2(13.3 \%)$ \\
\hline
\end{tabular}

The mean values of arterial $\mathrm{pH}$ and bicarbonate levels were $7.11 \pm 0.8$ and $13.3 \pm 7.1 \mathrm{mmol} / \mathrm{l}$, respectively. The mean value of hematocrit was $42.5 \pm 2.8 .12(80 \%)$ of the patients received intensive alkali therapy. Eight patients $(53.33 \%)$ were dialyzed once. Two patients (13.3\%) succumbed to death due to altered sensorium, metabolic acidosis and hypotension and died before hemodialysis.

\section{Laboratory profile}

\begin{tabular}{|l|c|}
\hline Biochemical variable & Mean SD \\
\hline Arterial $\mathrm{pH}$ & $7.11 \pm 0.8$ \\
\hline Bicarbonate & $13.3 \pm 7.1$ \\
\hline Lactate & $2.2 \pm 0.8$ \\
\hline Base deficit & $15.6 \pm 3.8$ \\
\hline PCV & $42.5 \pm 2.8$ \\
\hline
\end{tabular}

\section{Discussion}

Methyl alcohol or methanol $(\mathrm{CH} 3 . \mathrm{OH})$ or wood alcohol, is a colourless, volatile and toxic liquid. Accidental exposure to methanol may occur in large outbreaks as a result of contaminated alcoholic drinks, and several major outbreaks in developing countries have been associated with high morbidity and mortality. Methanol is metabolised by the alcohol dehydrogenase enzyme and converted to formaldehyde which is converted to formic acid by aldehyde dehydrogenase (ALDH) (Figure 1). The formic acid inhibits cytochrome oxidase in the electron transport chain and leads to cellular dysfunction and organ failure. The accumulation of toxic metabolites affects the end organs, including the retina and the brain, leading to visual impairment, blindness, with a classical 'snow field' pattern of visual loss and lesion in the basal ganglia. Visual impairment is due to optic nerve demyelination caused by the destruction of myelin by formic acid.

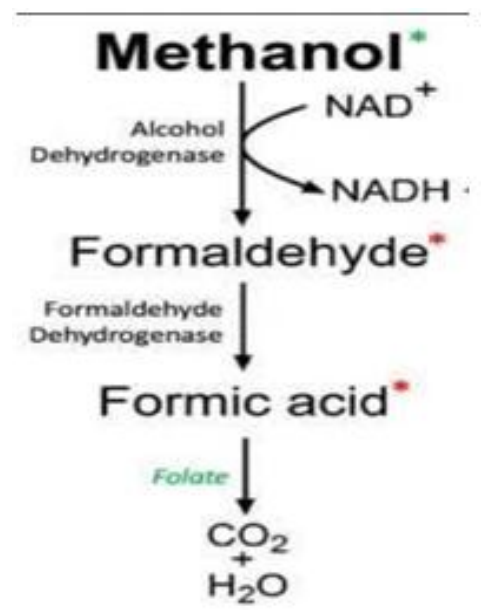

Figure 1: metabolism of methanol

Patients present with symptoms, 12-24 hours after ingestion of methanol. Gastrointestinal symptoms like pain abdomen, nausea, and vomiting are the most common symptoms. Neurological manifestations include headache, lethargy, confusion. Altered sensorium and comaare seen in individuals who consume large amounts. In this study, 2(13.3\%) patients developed altered sensorium and hypotension and had severe metabolic acidosis at the time of admission. 
Visual manifestations include blurring of vision and blindness.

Laboratory values include high anion gap metabolic acidosis with decreased bicarbonate levels. Early in the intoxication, serum osmolality can be increased, which is due to increased methanol concentrations. As methanol metabolism proceeds, the OG decreases and, because of the accumulation of toxic metabolites, the AG increases. In our study, metabolic acidosis is seen in $80 \%$ of cases. Rapid decision making, early and aggressive management is crucial to prevent the hazardous outcome of methanol toxicity.

Table 1 : Criteria of diagnosing methanol toxicity

1. Documented plasma methanol concentration $>20 \mathrm{mg} / \mathrm{dL}$. $(>200 \mathrm{mg} / \mathrm{L}$ ).

2. Documented recent history of ingesting toxic amounts of methanol and osmolal gap $>10 \mathrm{mOsm} / \mathrm{kg}$.

3. History or strong clinical suspicion of methanol poisoning with at least two of the following criteria :

a. Severe metabolic acidosis i.e. Arterial $\mathrm{pH}<7.3$

b. Serum bicarbonate $<20 \mathrm{meq} / \mathrm{L}(\mathrm{mmol} / \mathrm{L})$

c. Osmolal gap $>10 \mathrm{mOsm} / \mathrm{kg}$

Any one of the three

\section{Table 2 : Ethanol dosage regimens}

A. Loading Dose of Ethanol

1. Intravenous: $7.6-10 \mathrm{~mL} / \mathrm{kg}$ of a $10 \%$ solution in Dextrose $5 \%$. Ethanol is available as $5 \%$ or $10 \%$ solutions in Dextrose $5 \%$; the latter is preferred.

2. Oral : $0.8-1 \mathrm{~mL} / \mathrm{kg}$ of $95 \%$ Ethanol, administered PO in orange juice.

B. Maintenance Dose of Ethanol

\begin{tabular}{lcccc}
\hline & $\begin{array}{c}10 \% \text { ethanol } \\
\mathrm{IV} \mathrm{mL} / \mathrm{kg} / \\
\mathrm{hr})\end{array}$ & $\begin{array}{c}40 \% \text { ethanol } \\
\mathrm{PO}(\mathrm{mL} / \mathrm{kg} / \\
\mathrm{hr})\end{array}$ & $\begin{array}{c}95 \% \text { ethanol } \\
\mathrm{PO} / \mathrm{mg} / \mathrm{kg} / \\
\mathrm{hr})\end{array}$ & $\begin{array}{c}\text { Hemodialysis } \\
\text { with } 10 \% \\
\text { ethanol IV } \\
(\mathrm{mL} / \mathrm{kg} / \mathrm{hr})\end{array}$ \\
\hline $\begin{array}{l}\text { Moderate } \\
\text { drinker }\end{array}$ & 1.4 & 0.3 & 0.15 & 2.7 \\
$\begin{array}{l}\text { Chronic } \\
\text { drinker }\end{array}$ & 2 & 0.4 & 0.2 & 3.9 \\
\begin{tabular}{l} 
Nondrinker \\
\hline
\end{tabular} & 0.8 & 0.2 & 0.1 & 2.7 \\
\hline
\end{tabular}

The first treatment is to secure and maintain airway, breathing and circulation. Because methanol is rapidly absorbed, gastrointestinal decontamination using gastric lavage or activated charcoal is not recommended. General supportive care, i.e. mechanical ventilation, intravenous fluids, and vasopressors, may be indicated in severe intoxication. Initial treatment with sodium bicarbonate $1-2 \mathrm{mg} / \mathrm{kg}$ via intravenous route, bolus is required for patient with $\mathrm{pH}$ below 7.3, followed by maintenance infusion till arterial $\mathrm{pH}$ is above 7.35.
Treatment with ADH inhibitors, fomepizole (4methyl pyrazole) or ethanol delay the metabolism of methyl alcohol to toxic metabolite 'formate' and prevent its accumulation and toxicity. The loading dose of fomepizole is $15 \mathrm{mg} / \mathrm{kg}$ intravenously followed by $10 \mathrm{mg} / \mathrm{kg}$ every 12 hours, with adjustment for hemodialysis. We couldn't use fomepizole as it is not available. Comparison between fomepizole and ethanol in the treatment of methanol poisoning is given in table 3.Treatment with folinic or folic acid $50 \mathrm{mg}$ IV 6 hourly or orally as co-factor therapy accelerates the formic acid elimination as formic acid is converted to carbon dioxide and water by tetrahydrofolate synthetase, an enzyme that is dependent on folic acid. Hemodialysis enhances the removal of methanol and formic acid and corrects metabolic acidosis and is indicated in $\mathrm{pH}$ $<7.3$, methanol level $>50 \mathrm{mg} / \mathrm{dl}$ or visual loss and organ damage. Hemodialysis reduces the duration of antidotal treatment and, in most cases, the duration of hospitalisation. In this study, patients responded, and symptoms improved with hemodialysis and 13 patients are discharged after one week of hospitalisation, and two patients succumbed to death on the day of admission. The most probable cause of death is severe metabolic acidosis and hypotension.

\section{Comparison of fomepizole and ethanol in the} treatment of methanol poisoning

\begin{tabular}{|c|c|}
\hline Fomepizole & Ethanol \\
\hline Expensive & Inexpensive \\
\hline $\begin{array}{l}\text { Higher affinity for ADH than } \\
\text { ethanol }\end{array}$ & $\begin{array}{l}\text { Lower affinity for ADH than } \\
\text { fomepizole }\end{array}$ \\
\hline $\begin{array}{l}\text { Not available in all medical } \\
\text { centres }\end{array}$ & $\begin{array}{c}\text { Available in most clinical } \\
\text { centres }\end{array}$ \\
\hline Minimal adverse effects & $\begin{array}{l}\text { Significant adverse effects } \\
\text { possible: CNS depression, } \\
\text { hypoglycaemia and } \\
\text { hepatotoxicity. }\end{array}$ \\
\hline $\begin{array}{c}\text { Hospitalisation in ICU in } \\
\text { general not necessary }\end{array}$ & $\begin{array}{c}\text { Hospitalisation in ICU } \\
\text { necessary during treatment }\end{array}$ \\
\hline $\begin{array}{l}\text { Monitoring of fomepizole } \\
\text { blood levels not necessary }\end{array}$ & $\begin{array}{c}\text { Requires intensive monitoring } \\
\text { of ethanol and glucose blood } \\
\text { levels }\end{array}$ \\
\hline $\begin{array}{l}\text { Fomepizole increases the half- } \\
\text { life of methanol and EG, } \\
\text { therefore also consider using } \\
\text { haemodialysis }\end{array}$ & $\begin{array}{c}\text { Ethanol increases the half-life } \\
\text { of methanol and EG, therefore } \\
\text { also consider using } \\
\text { haemodialysis }\end{array}$ \\
\hline
\end{tabular}


In this study, all patients belong to low socioeconomic strata and are labourers by occupation. Patients are generally missed due to inadequate history, inadequate knowledge of the profile of symptoms of methanol poisoning. Patients are usually identified and treated when they present in mass casualty, which poses a significant challenge to the health care system.

\section{Conclusion}

Patients with methanol poisoning present with gastrointestinal, neurological, and visual symptoms. Rapid recognition, early and aggressive management has been emphasised to prevent the hazardous outcome. Hemodialysis improves the outcome in methyl alcohol poisoningby reducing the duration of antidotal treatment and shortening the hospital observation period.

Financial support and sponsorship: Nil.

Conflicts of interest: There are no conflicts of interest.

\section{References}

1. Methyl Alcohol Poisoning: A Manifestation of Typical Toxicity and Outcome Laxmi Nand*, Subhash Chander**, Rajesh Kashyap***, Dalip Gupta****, https://www.japi.org/q2f464c4/

2. ReynerLoza, Dimas Rodriguez, "A Case of Methanol Poisoning in a Child", Case Reports in Nephrology, vol. 2014, Article ID 652129, 3 pages, 2014. https://doi.org/10.1155/2014/652129

3. Kumar, Manish et al. "Single center experience of managing methanol poisoning in the hilly state of Uttarakhand: A cross sectional study." International journal of critical illness and injury science vol. $\quad 9,4 \quad$ (2019): $172-176$. doi:10.4103/IJCIIS.IJCIIS_49_19

4. Najari F, Baradaran I, Najari D. Methanol Poisoning and Its Treatment. International
Journal of Medical Toxicology and Forensic Medicine. 2020; 10(1): 26639. https://doi.org/10.32598/ijmtfm.v10i1.266 39

5. Rostrup M, Edwards JK, Abukalish M, Ezzabi M, Some D, Ritter H, et al. The methanol poisoning outbreaks in Libya 2013 and Kenya 2014. PLoS ONE. 2016;11:e0152676. [PMC free article] [PubMed] [Google Scholar]

6. Jarwani BS, Motiani PD, Sachdev S. Study of various clinical and laboratory parameters among 178 patients affected by hooch tragedy in Ahmedabad, Gujarat (India): A single center experience. J Emerg Trauma Shock. 2013;6:73-7. [PMC free article] [PubMed] [Google Scholar

7. Kute VB, Godara SM, Shah PR, Gumber MR, Goplani KR, Vanikar AV, et al. Hemodialysis for methylalcohol poisoning: A single-center experience. Saudi J Kidney Dis Transpl. 2012;23:3743. [PubMed]

8. Zyoud SH, Al-Jabi SW, Sweileh WM, Awang R, Waring WS. Bibliometric profile of the global scientific research on methanol poisoning (1902-2012). J Occup Med Toxicol. 2015;10:17. Published 2015 May 3. doi:10.1186/s12995-015-0062-

9. Bennett, Ivan L. JR. M.D.; Cary, Freeman H. M.D.; Mitchell, George L. JR. M.D.; Cooper, Manuel N. M.D. Acute Methyl Alcohol Poisoning: A review based on Experiences in an outbreak of 323 Cases, Medicine: December 1953 - Volume 32 Issue 4 - p 431-463.

10. Acute methanol poisoning 'the blind drunk'. West J Med. 1981;135(2):122-128.

11. Rietjens SJ, de Lange DW, Meulenbelt J. Ethylene glycol or methanol intoxication: which antidote should be used, fomepizole or ethanol? Neth J Med. 2014 Feb;72 (2):73-9. PMID: 24659589. (google scholar) 
12. Ravichandran R R, Dudani R A, Almeida A F, Chawla K P, Acharya V N. Methyl alcohol poisoning. (Experience of an outbreak in Bombay). J Postgrad Med [serial online] 1984 [cited 2020 Oct 21]; 30:69-74. Available from: https://www.jpgmonline.com/text.asp?198 4/30/2/69/546

13. Trivedi TH, Yeolekar ME, Shejale SB, et al. Methanol poisoning in medical intensive care unit. J Assoc Physicians India 2001;49;257-258.

14. Kumar P, Gogia A, Kakar A, Miglani P. An interesting case of characteristic methanol toxicity through inhalational exposure. J Family Med Prim Care. 2015;4(3):470-473. doi:10.4103/22494863.161359

15. Gupta N, Sonambekar AA, Daksh SK, Tomar L. A rare presentation of methanol toxicity. Ann Indian AcadNeurol. 2013;16:249-51. [PMC free article] [PubMed] [Google Scholar].

16. Blanco M, Casado R, Vázquez F, Pumara JM. CT and MR imaging findings in methanol intoxication. AJNR Am J Neuroradiol. 2006;2013:452-4. [PubMed] [Google Scholar]. 